\title{
Comparative Effect of Forward and Backward Stair Climbing on Cardio-respiratory Parameters of Apparently Healthy Young Adults
}

\author{
ADEGOKE, B.O.A., ${ }^{1}$ OLAGBEGI, O.M. ${ }^{2}$ \\ ${ }^{1}$ Department of Physiotherapy, College of Medicine, University of Ibadan, Ibadan, Nigeria \\ ${ }^{2}$ Department of Physiotherapy, Federal Medical Centre, Owo, Ondo State, Nigeria \\ Correspondence \\ O.M.Olagbegi・E-mail: olagbegioladapo@yahoo.com
}

\begin{abstract}
SUMMARY
Forward stair climbing (FSC) is associated with cardiovascular fitness benefits, but the training effects of backward stair climbing (BSC) have not been reported in the literature. This study compared the effects of 8 weeks of FSC and BSC on the cardiovascular parameters of apparently healthy young adults.

Forty apparently healthy young adults, aged 18-30 years were recruited consecutively and assigned to FSC and BSC training groups. Thirty-one subjects (16 FSC and 15 BSC) completed the study. The FSC subjects climbed a stepladder in the forward direction while the BSC subjects did so in the backward direction. Each paced ascent and descent lasted 8 seconds for both FSC and BSC groups. Systolic blood pressure (SBP) and diastolic blood pressure (DPB), heart rate (HR) and cardiovascular endurance (CE) were evaluated at baseline, and at the end of the $4^{\text {th }}$ and $8^{\text {th }}$ weeks of the study. Data was analysed using mean, standard deviation, percentages, one-way of variance (ANOVA) and independent t-test. Level of significance was set at 0.05 .

The groups were not significantly different $(\mathrm{p}>0.05)$ in their cardiovascular parameters at weeks 0,4 , and 8 . The FSC group had significant improvement $(p=0.045)$ in CE. The percentage change in CE by FSC $(11.06 \pm$ $11.44 \%)$ was significantly greater $(\mathrm{p}=0.006)$ than that by BSC $(-0.60 \pm 10.41 \%)$. Both interventions had no significant effect on the participants' systolic blood pressure, diastolic blood pressure and heart rate.

Forward stair climbing is more effective in improving the $\mathrm{CE}$ of apparently healthy young adults and, hence, for improving cardiovascular endurance in rehabilitation and athletic training.
\end{abstract}

KEY WORDS: Stair climbing, blood pressure, cardiovascular endurance

\section{INTRODUCTION}

Stair climbing (a common training procedure in physiotherapy and sports science) has been reported to be highly associated with cardiovascular and fitness benefits (Boreham et al, 2000). Teh and Aziz (2002) described stair climbing as a vigorous-intensity physical activity, with oxygen uptake reaching approximately $80 \%$ of maximal values in young adults, which corresponds to nearly 10 metabolic equivalents (METS) of energy expenditure. Stair use, especially when climbing, is a vigorous physical activity that can be easily engaged in by most of the population and several studies have shown it to be effective in improving aerobic capacity and cardiovascular disease risk factors (Meyer et al, 2009).

Studies in the United Kingdom from the mid-90s have shown that people were being encouraged to deliberately use the stairs during their daily activities, when it was observed that the use of escalators had eroded its use in most workplaces (Blammey et al, 1995; Kerr et al, 1995; Mutrie and Blammey, 2000). The work of Boreham et al (2005) showed that 8 weeks of stair climbing produced a $17.1 \%$ increase in maximum oxygen uptake $\left(\mathrm{VO}_{2} \max \right)$ and 
a $7.7 \%$ reduction in low density lipoprotein in young women who were previously sedentary. Thus, they concluded that short bouts of stair climbing throughout the day can favourably alter important cardiovascular risk factors in previously sedentary young women, and that such exercise may easily be incorporated into the working day and, consequently, be promoted by public health guidelines.

Cardiovascular endurance, defined as the ability of the total body to sustain prolonged, rhythmical exercise, is related to the development of cardiovascular and respiratory systems (Wilmore, 1982). It is a measure of fitness which typifies the ability of an individual to perform large muscle dynamic exercises, such as walking, swimming or biking, for a long period of time (Kisner and Colby, 1996). The best objective laboratory measure of $\mathrm{VO}_{2} \max$ is cardiovascular endurance (Wilmore, 1982), and methods for its estimation include: Cycle Ergometer test, AstrandRhyming test, Harvard 3-minutes test (when testing large numbers of subjects), 1.5 mile run, 12-minute run, 1 mile walk and Rockport fitness walking, which is used for inactive and older individuals (Verducci, 1980; Kisner and Colby, 1996).

Backward walking has been reported to produce significantly greater metabolic responses compared to forward walking at $0 \%$ and $5 \%$ treadmill grades (Chaplouka et al, 199). Myatt et al (1995) also reported that backward walking required $38-119 \%$ energy consumption than forward walking at the same speed. There is however a dearth of literature on the comparative effects of forward and backward stair climbing on cardiovascular parameters, such as blood pressure, heart rate, and cardiovascular endurance. This study thus sought to answer the question: would there be any significant difference in the effects of 8-week forward and 8-week backward stair climbing (FSC and BSC) exercise programmes on the diastolic blood pressure (DBP) and systolic blood pressure (SBP), heart rate $(\mathrm{HR})$ and cardiovascular endurance $(\mathrm{CE})$ of apparently healthy young adults.

\section{METHODOLOGY}

\section{Participants}

Forty apparently healthy young adults aged 18-30 years were recruited from the University of Ibadan and University College Hospital communities. The participants had no history of fractures (in the past 12 months) nor any evidence of paralysis or weakness of the lower limb muscles. None of the subjects was participating in any active sporting activity at the time of the study. They were allotted numbers once they became available and assigned to either the forward stair climbing (FSC) or backward stair climbing (BSC) group based on their number (Sorinola and Akegbeyale, 2001). There were 20 subjects in each group. Our sample size was guided by the sample sizes used in related studies by Loy et al (1994), Boreham et al (2000) and Boreham et al (2005), which involved sample sizes of 9, 12 and 15 apparently healthy individuals respectively.

\section{Research Design}

A pre-test/post-test quasi-experimental design was used for the study.

\section{Procedure}

The approval of the University of Ibadan/University College Hospital Joint Institutional Review Committee was sought and obtained before the commencement of the study. Written informed consent was also sought and obtained from the participants after the experimental procedures had been explained to them. Participants' ages as at last birthday were recorded in years; their heights and body weights were measured in centimetres and kilogrammes using standardized procedures.

\section{Test and Measurements}

\section{a. Blood pressure}

This was taken with the subject in sitting position, with the arms horizontally supported at the heart level. Diastolic and systolic blood pressures were then taken with the stethoscope and sphygmomanometer (Accoson, England) using the conventional method described by Schmitz (1988), and recorded in $\mathrm{mmHg}$.

\section{b. Heart rate (Pulse rate)}

After 5 minutes pre-exercise rest, the subject's radial pulse was taken in beats per minute, with the forearm slightly pronated and the wrist slightly flexed, as described by Schmitz (1988). Timing was done with a stopwatch (Nokia 3110c).

\section{c. Harvard 3-minute step test}

Step benches $($ male $=40 \mathrm{~cm}$ high, $28 \mathrm{~cm}$ wide; female $=$ $30 \mathrm{~cm}$ high, $28 \mathrm{~cm}$ wide) according to Amusa and Udoh (1982), were used for this test. The subjects were dressed in light apparel (a top vest and a pair of shorts). A cadence of 96 beats per minute was set with the metronome 
(Samick, Spain) to achieve a pace of 24 steps per minute (Verducci, 1980). A complete step consists of four counts thus:

1. One foot placed on the bench - one foot

2. The second foot placed on the bench

3. The first foot withdrawn to the floor

4. The second foot withdrawn to the floor (Amusa and Udoh, 1982).

Stepping up and down was done as long as the participant maintained pace with the metronome or showed no evidence of fatigue for a period of 3 minutes. Immediately after the test, the subject was asked to sit on a comfortable chair and the radial pulse was taken for 30 seconds each at one, two and three minutes post-exercise (Amusa and Udoh, 1982). The cardiovascular endurance index was then estimated using the formula:

Cardiovascular Endurance Index $=$ Duration of exercise in $\times 100$

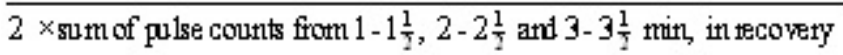

Blood pressure, heart rate and cardiovascular endurance were assessed at the beginning of the study, and at the end of weeks 4 and 8 of the training programme.

\section{The Training Programme}

\section{a. Forward stair climbing}

A wooden stepladder with four steps about $15 \mathrm{~cm}$ high on the ascent side, and three steps $20 \mathrm{~cm}$ high on the descent side, was used for the stair climbing training programme. Its total height was $60 \mathrm{~cm}$ and its gradient on the ascent and descent sides were 0.67 and 0.91 respectively. All steps were $50 \mathrm{~cm}$ wide. Participants in the FSC group ascended and descended the stepladder in the forward direction without holding the rails. Each ascent and descent lasted a total of eight seconds, with the participant's alternate foot stepping on a stair every second as the researcher made a count of $1,2,3$ to 8 . The subjects had three repeated ascents and descents per session during weeks 1 and 2 of the training.

Progression: The training programme was progressed as follows:

Weeks 3 and 4: 6 ascents and descents/session;

Weeks 5 and 6: 9 ascents and descents/session;

Weeks 7 and 8: 12 ascents and descents/session

(Boreham et al, 2000)

\section{b. Backward stair climbing}

Participants in the BSC group ascended and descended the stepladder in the backward direction. Pace and progression were the same as for the forward stair climbing group. Training took place thrice weekly (Mondays, Wednesdays and Fridays) between 8.00 and 12.00 hours.

\section{Data Analysis}

The data were analysed using descriptive statistics of mean, standard deviation and percentages. The one-way analysis of variance (ANOVA) was used to compare the mean of the SBP, DPB, HR and CE of subjects at 0,4 , and 8 weeks of training. Duncan post-hoc analysis was utilized to locate pairs that significantly differed. The independent t-test was used to compare the mean SBP, DBP, and CE of both groups at the beginning of the study. It was also used to compare the mean changes in the SBP, DBR, HR, and CE of the two groups at the end of the 8-week programme. Level of significance was set at 0.05

\section{RESULTS}

Thirty-one $(77.5 \%)$ of the 40 participants (16 FSC group and 15 BSC group) completed the study and only their data were analyzed. Twenty (64.5\%) of the subjects were female. The biodata of the subjects in the FSC and BSC groups are compared in table 1. Participants in the FSC group were significantly older $(p=0.005)$ than those in the BSC, but the groups did not differ in their heights and weights. The cardiovascular parameters of participants in the two groups are compared in table 2. The groups did not differ significantly $(\mathrm{p}>0.05)$ in their SBP, DBP, HR and CE at weeks 0,4 , and 8 of the study.

Table 1. Biodata of participants

\begin{tabular}{l|l|l|l}
\hline Variable & $\begin{array}{l}\text { FSC GRP }(\mathrm{N}= \\
16)\end{array}$ & $\begin{array}{l}\text { BSC GRP }(\mathrm{N}= \\
15)\end{array}$ & $\mathrm{P}$ \\
& Mean $\pm \mathrm{SD}$ & Mean $\pm \mathrm{SD}$ & \\
\hline Age (years) & $26.06 \pm 3.09$ & $23.2 \pm 2.57$ & $0.005^{*}$ \\
Height $(\mathrm{cm})$ & $169.75 \pm 11.68$ & $169.33 \pm 6.39$ & 0.910 \\
Body weight $(\mathrm{kg})$ & $61.13 \pm 12.76$ & $58.53 \pm 4.85$ & 0.820 \\
\hline
\end{tabular}

* Indicates significant difference at $\alpha=0.05$

The one-way analysis of variance (ANOVA) was used for within-group comparison of the subjects' SBP, DBP, HR and $\mathrm{CE}$ at weeks 0,4 and 8 (table 3 ). Significant difference $(p=0.045)$ occurred only in the CE for the FSC group. Duncan post-hoc analysis indicated that the significance 
Comparative Effect of Forward and Backward Stair Climbing on Cardio-respiratory Parameters

occurred between weeks 0 and week 8 of the study. The training effects of forward and backward stair climbing at the end of the study are compared on table 4 . There was a significant difference $(\mathrm{p}=0.006)$ between the change in CE for the FSC group $(11.06 \pm 11.44)$ and that for the BSC group $(-0.60 \pm 10.41)$. The percentage changes in the variables for each group at the end of the study are presented in table 5. The FSC group experienced more gain in CE $(27.45 \pm 31.19 \%)$ and more reduction in HR (-0.60 $\pm 8.33 \%)$, while the BSC group experienced a reduction in DBP $(-2.12 \pm 8.73 \%)$.

\section{DISCUSSION}

The primary objective of this study was to compare the training effects of forward and backward stair climbing (FSC and BSC) exercise programmes on the cardiorespiratory parameters (resting blood pressure, heart rate, and cardiovascular endurance) of apparently healthy young adults. At the commencement of the study, the groups were not significantly different in any of the variables investigated. Thus, the two groups were equivalent at the beginning of the study, and any subsequent difference between them could largely have been due to the difference between the interventions received by the groups.

Table 2. Comparison of FSC and BSC groups at weeks 0,4 and 8 of the study

\begin{tabular}{|c|c|c|c|c|}
\hline Variable & $\begin{array}{l}\text { SBP }(\mathrm{mmHg}) \\
\text { Mean } \pm \mathrm{SD}\end{array}$ & $\begin{array}{l}\text { DBP }(\mathrm{mmHg}) \\
\text { Mean } \pm \text { SD }\end{array}$ & $\begin{array}{l}\text { HR (beats/min) } \\
\text { Mean } \pm \text { SD }\end{array}$ & $\begin{array}{l}\text { CE }(\%) \\
\text { Mean } \pm \text { SD }\end{array}$ \\
\hline \multicolumn{5}{|c|}{ Week 0} \\
\hline FSC GRP & $105.00 \pm 8.17$ & $73.63 \pm 7.27$ & $76.81 \pm 8.63$ & $54.94 \pm 13.37$ \\
\hline BSC GRP & $106.67 \pm 14.48$ & $72.67 \pm 7.99$ & $75.07 \pm 7.59$ & $64.93 \pm 17.36$ \\
\hline $\mathrm{P}$ & 0.693 & 0.729 & 0.555 & 0.082 \\
\hline \multicolumn{5}{|c|}{ Week 4} \\
\hline FSC GRP & $107.83 \pm 8.44$ & $71.25 \pm 5.46$ & $73 . .44 \pm 11.74$ & $61.25 \pm 11.9$ \\
\hline BSC GRP & $107.33 \pm 10.33$ & $72.40 \pm 7.06$ & $74.740 \pm 8.15$ & $63.27 \pm 13.39$ \\
\hline$\underline{P}$ & 0.990 & 0.614 & 0.794 & 0.651 \\
\hline \multicolumn{5}{|c|}{ Week 8} \\
\hline FSC GRP & $106.13 \pm 8.28$ & $74.13 \pm 6.30$ & $75.88 \pm 6.22$ & $66.00 \pm 11.87$ \\
\hline BSC GRP & $107.33 \pm 8.83$ & $70.93 \pm 8.31$ & $75.20 \pm 11.41$ & $64.40 \pm 14.19$ \\
\hline $\mathrm{P}$ & 0.697 & 0.236 & 0.838 & 0.735 \\
\hline
\end{tabular}

Table 3. ANOVA for within group comparison of participants' variables across weeks 0,4 and 8

\begin{tabular}{|c|c|c|c|c|}
\hline Variable & $\begin{array}{l}\text { WK } 0 \\
\text { Mean } \pm \text { SD }\end{array}$ & $\begin{array}{l}\text { WK } 4 \\
\text { Mean } \pm S D\end{array}$ & $\begin{array}{l}\text { WK } 8 \\
\text { Mean } \pm S D\end{array}$ & \\
\hline \multicolumn{5}{|c|}{ FSC GROUP } \\
\hline $\mathrm{SBP}(\mathrm{mmHg})$ & $105.00 \pm 14.48^{*}$ & $107.38 \pm 8.44 *$ & $106.13 \pm 8.28^{*}$ & 0.722 \\
\hline $\mathrm{DBP}(\mathrm{mmHg})$ & $73.63 \pm 7.27 *$ & $71.25 \pm 5.46^{*}$ & $74.13 \pm 6.30^{*}$ & 0.404 \\
\hline $\mathrm{HR}$ (beats/min) & $76.81 \pm 8.63 *$ & $73.44 \pm 11.74 *$ & $75.88 \pm 6.20^{*}$ & 0.564 \\
\hline $\mathrm{CE}(\%)$ & $54.94 \pm 13.37$ & $61.25 \pm 11.19^{*}$ & $66.00 \pm 11.87 *$ & $0.045 *$ \\
\hline \multicolumn{5}{|c|}{ BSC Group } \\
\hline $\mathrm{SBP}(\mathrm{mmHg})$ & $106 \pm 14.48^{*}$ & $107.33 \pm 10.33^{*}$ & $107.33 \pm 8.83^{*}$ & 0.983 \\
\hline $\mathrm{DBP}(\mathrm{mmHg})$ & $72.63 \pm 7.99^{*}$ & $72.40 \pm 7.06^{*}$ & $70.93 \pm 8.31 *$ & 0.808 \\
\hline $\mathrm{HR}$ (beats/min) & $72.07 \pm 7.59 *$ & $74.40 \pm 8.15^{*}$ & $75.20 \pm 8.31^{*}$ & 0.968 \\
\hline $\mathrm{CE}(\%)$ & $64.93 \pm 17.36^{*}$ & $63.27 \pm 13.34 *$ & $64.40 \pm 14.91 *$ & 0.953 \\
\hline
\end{tabular}

*: Indicates significant difference at $\alpha=0.05$

Table 4. Independent t-test for comparison of mean changes in the groups' variables at the end of the study

\begin{tabular}{l|l|l|l}
\hline Variable & $\begin{array}{l}\text { FSC GRP }(\mathrm{N}=16) \\
\text { Mean } \pm \mathrm{SD}\end{array}$ & $\begin{array}{l}\text { BSC GRP }(\mathrm{N}=15) \\
\text { Mean } \pm \mathrm{SD}\end{array}$ & $\mathrm{P}$ \\
\hline $\mathrm{SBP}(\mathrm{mmHg})$ & $1.13 \pm 5.46$ & $0.67 \pm 8.84$ & 0.896 \\
$\mathrm{DBP}(\mathrm{mmHg})$ & $0.50 \pm 4.23$ & $1.73 \pm 6.41$ & 0.098 \\
HR (beats/min) & $-0.94 \pm 6.34$ & $0.13 \pm 7.43$ & 0.670 \\
CE $(\%)$ & $11.06 \pm 11.44$ & $-0.60 \pm 10.41$ & $0.006^{*}$ \\
\hline
\end{tabular}

*: Indicates significant difference at $\alpha=0.05$
Table 5. Percentage changes in variables in each group at the end of the study

\begin{tabular}{l|l|l}
\hline Variable & $\begin{array}{l}\text { FSC Group } \\
\% \text { Increas/decrease } \\
\text { Mean } \pm \text { SD }\end{array}$ & $\begin{array}{l}\text { BSC Group } \\
\% \text { Increas/decrease } \\
\text { Mean } \pm \text { SD }\end{array}$ \\
\hline SBP (mmHg) & $1.15 \pm 5.43$ & $1.46 \pm 8.03$ \\
DBP (mmHg) & $0.95 \pm 5.79$ & $-2.12 \pm 8.73$ \\
HR (beats/min) & $-0.60 \pm 8.33$ & $1.07 \pm 8.93$ \\
CE $(\%)$ & $27.45 \pm 31.19$ & $2.55 \pm 20.30$ \\
\hline
\end{tabular}

$\%$ Change $=$ value at week $8-$ value at week $0 /$ value at week $0 \mathrm{x}$ 100 
Effects of Forward and Backward Stair Climbing on Participants' Cardiovascular Parameters

Backward stair climbing had no significant effect on any of the cardiovascular parameters studied, while forward stair climbing had significant effect on only cardiovascular endurance. The findings from this study, concerning the effect of stair climbing on blood pressure and heart rate, are at variance with known effects of endurance exercises such as stair climbing on resting cardiovascular parameters of participants. Physical training and various forms of aerobic exercise are generally known to bring about a reduction in cardiovascular parameters (Fox and Matthews, 1981). Boreham et al (2000) observed significant reductions in $\mathrm{VO}_{2}$ max heart rate and blood lactate of 12 previously sedentary young women, aged 18-22 years, after a 7-week forward stair climbing programme. Adiputra et al (1996) also observed significant decreases in resting heart rate, blood pressure and percentage body fat in sixty young male adults after an 8-week Balinese dance exercise programme.

The findings of this study suggest that both FSC and BSC exercise procedures, as used in this study, might not have tasked the cardiovascular systems of participants enough to bring about a significant improvement in blood pressure and heart rate. This may be due to the number of steps and the height of the stairs used in this study. The stairs had just four steps and a height of $60 \mathrm{~cm}$, compared to the public staircase of 199 steps utilized by Boreham et al (2000). The observed difference between the effects of stair climbing on cardiovascular parameters in both studies could also be explained by the difference between the speeds of stair climbing in the two studies. Though there was an overload in terms of increase in the number of ascents in both studies, in this study, ascent and descent lasted 8 seconds with a pace of 1 step per second, in comparison to a paced ascent lasting 135 seconds with no timed descent in the work of Boreham et al (2000).

The FSC exercise programme however produced a significant increase in cardiovascular endurance at the end of the $8^{\text {th }}$ week. Loy et al (1994) had similarly observed a significant increase in $\mathrm{VO}_{2} \mathrm{max}$ in nine middle-aged sedentary females at the end of a 12-week stair climbing programme. The finding is also consistent with the work of Loy et al (1993) who observed a significant increase in the $\mathrm{VO}_{2}$ max of eleven young adults after a 9-week stair climbing programme. It also supports the findings of Boreham et al (2005), who reported a $17.1 \%$ increase in the $\mathrm{VO}_{2}$ max of 15 previously sedentary women following 8 weeks of short bouts of stair climbing. Boreham et al (2000) had earlier observed a significant reduction in the oxygen uptake $\left(\mathrm{VO}_{2} \max \right)$ (an indication of improvement in aerobic capacity) of twelve young women who were previously sedentary.

\section{Comparison of Effects of Forward and Backward Stair} Climbing on Participants' Cardiovascular Parameters

Forward and backward stair climbing had similar effects on the participants' cardiovascular parameters except for cardiovascular endurance, in which forward stair climbing was significantly better. The findings in this study of backward stair climbing will be compared with those in the study of backward walking, since there are no published studies on backward stair climbing, on the presumption that the metabolic and mechanical demands of stair climbing and walking may be similar. Backward walking on the treadmill has been reported to produce significantly greater metabolic responses compared to forward walking at the same speed (Chaloupka et al, 1995). Unfortunately, participants' metabolic responses were not compared in this study.

Forward stair climbing resulted in a significant improvement in the subjects' cardiovascular endurance, when compared to backward stair climbing of the same intensity and duration. This seems to be at variance with the findings of Flynn et al (1994), who observed that backward walking at a speed of $1.79 \mathrm{~m} / \mathrm{sec}$ produced a similar rate of oxygen consumption as forward walking. It was expected that due to the seeming awkwardness of the act of climbing the stairs backward, the subjects' cardiovascular system would be tasked more, thus resulting in better improvement in their cardiovascular endurance. This contrary finding is difficult to explain.

Further, the comparison of percentage changes effected in the cardiovascular parameters indicate that backward stair climbing achieved more reduction in subjects' diastolic blood pressure, while forward stair climbing achieved appreciable gain in cardiovascular endurance and some reduction in resting heart rate, but no reduction in the resting values of other cardiovascular parameters. Although the observed significant effects of forward stair climbing were only evident at the end of the $8^{\text {th }}$ week of the study, the finding provides support for the already established fact in the literature that a forward stair climbing exercise programme is efficacious in improving cardiovascular endurance. 


\section{CLINICAL IMPLICATION/ RECOMMENDATION}

Forward stair climbing effected more significant gains in cardiovascular endurance and more reduction in resting heart rate (though not statistically significant) than backward stair climbing. Backward stair climbing however resulted in a reduction in diastolic blood pressure while forward stair climbing did not. French (1988) emphasized the need to always distinguish between statistical significance and practical and/or clinical significance. Forward stair climbing is recommended because it is easier to engage in during activities of daily living for the improvement of cardiovascular endurance in rehabilitation and athletic training. However, considering the observed effect of backward stair climbing on diastolic blood pressure, there is a need for further studies to examine the effect of backward stair climbing on hypertension in young adults. The short stair frame (step ladder) used in this study appeared not to have provided enough training load on the cardiovascular system; future studies should therefore make use of higher stairs like a public staircase. Verducci (1980) reported just a fair correlation between $\mathrm{VO}_{2}$ max measured using the Harvard step test and values obtained with instruments like the treadmill and bicycle ergometer. Future studies may need to employ these equipment in the assessment of $\mathrm{VO}_{2}$ max. There is also the need to involve larger sample sizes and, perhaps, investigate and compare the efficacy of forward and backward stair climbing in conditions like hypertension and obesity.

\section{References}

Adiptura, N., P. Alex, D.P. Sutjana, K. Tirtayasa K and A. Manuaba. 1996. Balinese dance exercises improve the maximum aerobic capacity. Journal of Human Ergology 25(1): 25-9.

Amusa, L.O. and C.O. Udoh 1982. Dynamics of Physical Fitness. Osogbo: Adebara Publishers. pp. 2.

Blamey, A., N. Mutrie and T. Aitchison 1995. Health promotion by encouraged use of stairs. British Medical Journal 311: 289290.

Boreham, C.A., R.A. Kennedy, M.H. Murphy, M. Tully, W.F. Wallace and I. Young 2005. Training effects of short bouts of stair climbing exercise in previously sedentary young women. British Journal of Sports Medicine 39: 590-593.

Boreham, C.A, W.F. Wallace and A. Nevil (2000). Training effects of accumulated stair climbing exercise in previously sedentary young women. Preventive Medicine 30(4): 277-81.
Chaloupka, E.C., J. Kang, M.A. Mastrangelo and M.S. Donnely. 1997. Cardio-pulmonary and metabolic responses during forward and backward walking. Journal of Orthopaedics Sports and Therapy 25(2):113-118.

Flynn, T.W., S.M. Connery, M.K. Simutok, R.J. Zeballos and I.M. Weisman 1994. Forward and backward walking and running. Medicine and Science in Sports and Exercise 26(1): 89-94.

Fox E.L. and Matthews D.K. 1981. The Physiological Basis of Physical Education and Athletics $3^{\text {rd }}$ ed. Philadelphia: CBS College Publishing. pp.139-162.

French, S. 1988. How significant is statistical significance? A critique of the use of statistics in research. Physiotherapy 74 : 266-268.

Kerr, J., F. Eves and D. Carrol. 2000. Posters can prompt less active people to use the stairs. Journal of Epidemiology and Community Health 54(12): 942-943.

Kisner, C. and L.A. Colby. 1996. Therapeutic Exercises: Foundation and Techniques $3^{\text {rd }}$ ed. New Delhi, India: Japee Brothers. pp. 112-113.

Loy, S.F., L.M. Conley, E.R. Sacco, W.J. Vincent, G.J. Holland, S.G. Sletten and P.R. Trueblood 1994. Effects of stair climbing on $\mathrm{VO}_{2}$ max and quadriceps strength in middle-aged females. Medicine and Science in Sports and Exercise 26(2): 241-247.

Loy, S.F., G.J. Holland, D.L. Mutton, J. Snow, W.J. Vincent, J.J. Hoffmann and S. Shaw 1993. Effects of stair climbing vs run training on treadmill and track performance. Medicine and Science in Sports and Exercise 25(11): 1275-1278.

Meyer, P., B. Kayser and F. Mach 2009. Stair use for cardiovascular disease prevention. European Journal of Cardiovascular Prevention and Rehabilitation 16 (Supp12): S17-S18.

Mutrie, N. and A. Blamey. 2000. Encouraging stair walking. British Journal of Sports Medicine 34: 144.

Myatt, A., R.. Baxter, R.. Dougherty, G. Williams, J. Halle and F. Underwood. 1995. The cardiovascular cost of backward walking at selected speeds. Journal of Orthopaedics Sports and Physical Therapy 25(2): 133-188.

Schmitz, T.J. 1988. In: O'sullivan S.B, Schmitz T.J. (eds). Physical Rehabilitation and Treatment $2^{\text {nd }}$ ed. Philadelphia: F.A. Davis Company, p.14.

Sorinola, I.O. and A.A. Akegbeyale 2001. Effects of cooling on muscle strengthening. Journal of the Nigeria Medical Therapist 6(1): 17-20.

Teh, K.C. and A.R. Aziz. 2002. Heart rate, oxygen uptake, and energy cost of ascending and descending stairs. Medicine and Science in Sports and Exercise 34: 695-699.

Verducci, F.M. 1980. Measurement Concepts in Physical Education. Toronto: C.V, Mosby Company: pp. 261-275.

Wilmore, J.H. 1982. Training for Sports and Activity: The Physiological Basis of the Conditioning Process. $2^{\text {nd }}$ ed. Boston: Allyn and Bacon, Inc. pp. 105-118. 